\title{
Operando bulk and interfacial characterization for electrochemical energy storage: Case study employing isothermal microcalorimetry and X-ray absorption spectroscopy
}

\author{
Wenzao Li1 ${ }^{1,2, b)}$, Mallory N. Vila ${ }^{1,2, b)}$, Lisa M. Housel ${ }^{1,3, b)}$, Nahian Sadique ${ }^{1,2}$, \\ Genesis D. Renderos ${ }^{1,2}$, Steve Ehrlich ${ }^{5}$, David C. Bock ${ }^{1,3}$, Lei Wang ${ }^{1,3}$, \\ Kenneth J. Takeuchi ${ }^{1,2,3,4}$, Esther S. Takeuchii ${ }^{1,2,3,4}$, Amy C. Marschilok ${ }^{1,2,3,4, a)}$ (D \\ ${ }^{1}$ Institute for Electrochemically Stored Energy, State University of New York at Stony Brook, Stony Brook, NY 11794, USA \\ ${ }^{2}$ Department of Chemistry, Stony Brook University, Stony Brook, NY 11794, USA \\ ${ }^{3}$ Interdisciplinary Science Department, Brookhaven National Laboratory, Upton, NY 11973, USA \\ ${ }^{4}$ Department of Materials Science and Chemical Engineering, Stony Brook University, Stony Brook, NY 11794, USA \\ ${ }^{5}$ National Synchrotron Light Source II, Brookhaven National Laboratory, Upton, NY 11973, USA \\ a) Address all correspondence to this author. e-mail: amy.marschilok@stonybrook.edu amarschilok@bnl.gov \\ b) These authors contributed equally to this work. \\ Received: 2 June 2021; accepted: 11 August 2021; published online: 25 October 2021
}

The global shift to electricity as the main energy carrier will require innovation in electrochemical energy storage (EES). EES systems are the key to the "electron energy economy," minimizing losses and increasing reliability between energy supply and demand. However, steep challenges such as cost, cycle/calendar life, energy density, material availability, and safety limit widespread adoption of batteries for large-scale grid and vehicle applications. Battery innovation that meets today's challenges will require new chemistries, which can originate from understanding charge transport phenomena at multiple time and length scales. The advancement of operando characterization can expedite this progress as changes can be observed during battery function. This article highlights progress in bulk and interfacial operando characterization of batteries. Specifically, a case study involving $\mathrm{Fe}_{3} \mathrm{O}_{4}$ is provided demonstrating that combining X-ray absorption spectroscopy and isothermal microcalorimetry can provide real-time characterization of productive faradaic redox processes and parasitic interfacial reactions during (de)lithiation.

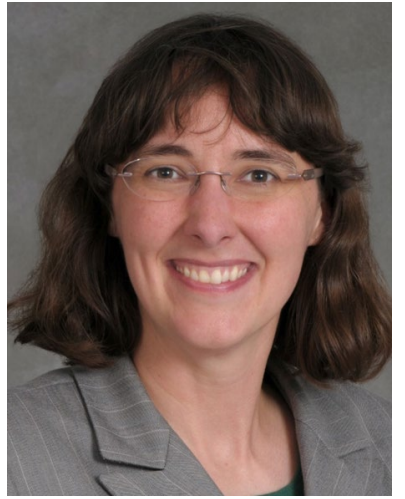

Amy Marschilok
Amy Marschilok is an Associate Professor in the Department of Chemistry at Stony Brook University, where she is an Adjunct Faculty in the Departments of Materials Science and Engineering and Chemical and Molecular Engineering and Co-Director of the Institute for Electrochemically Stored Energy. Dr. Marschilok holds a Joint Appointment at Brookhaven National Laboratory, where she serves as Energy Storage Division Manager and Energy Systems Division Manager in the Interdisciplinary Science Department. She also serves as Deputy Director for the Center for Mesoscale Transport Properties (http://www.stonybrook.edu/commcms/m2m/index.html), an Energy Frontier Research Center funded by the U.S. Department of Energy. Dr. Marschilok was previously employed as a Senior Scientist in the Medical Battery Research and Development group at Greatbatch Inc., where she was recognized as a Visionary of the Year. Before joining Greatbatch Inc, she received her B.A. and Ph.D. in chemistry with a BA in English at the University at Buffalo. Her current research centers on materials and electrode concepts for high power, high energy density, extended life batteries; investigation of electrochemical materials science; and operando investigations of energy storage materials and systems. 


\section{Introduction}

\section{Operando characterization of electrochemical energy storage}

Electrochemical energy storage is critical to achieve an "electron energy economy," where electricity generated by renewable resources powers all end-use applications. Rechargeable lithiumion batteries are among the most adopted energy storage systems; however, demands for higher power and energy densities, longer lifetime, and more rigorous safety assurance require significant material chemistry and engineering innovation. Challenges for lithium-ion batteries include sluggish ion transport due to inhomogeneous material phase transitions, irreversible electrode-electrolyte parasitic reactions, and energy losses arising from heat dissipation. Therefore, the ability to characterize the structural evolution, electrolyte decomposition, and thermal behaviors concomitant with the battery's electrochemistry represent an important approach toward solving the complex technical challenges of rechargeable batteries.

Operando characterization is at the forefront of battery research [1]. Unlike ex-situ characterization, which requires removing battery components from the cell body, operando characterization is non-destructive revealing synchronous electrochemical information that reflects working conditions when current is applied. The majority of operando battery characterization relies on electromagnetic (X-rays, optical) or particle radiation including angle and energy dispersive $\mathrm{X}$-ray diffraction (ADXRD, EDXRD), X-ray absorption spectroscopy (XAS), transmission X-ray microscopy (TXM), X-ray microfluorescence ( $\mu$-XFM), neutron powder diffraction (NPD), transmission electron microscopy (TEM), nuclear magnetic resonance (NMR), and Raman spectroscopy. These techniques have led to advances in understanding the charge storage mechanisms that govern next generation battery chemistries by detecting structural and chemical changes at the electrodes and electrode/electrolyte interphases. However, the listed optical and X-ray based operando techniques often require distinct cell configurations, access to specialty facilities such as synchrotron light sources, and significant experience in conducting electrochemical measurements and collecting/analyzing large data sets of spectra. Additionally, exposure to light, electrons, neutrons, and X-rays can potentially change battery materials overtime leading to possible ambiguity in the results depending on the system. Therefore, non-radiation operando methods can prove indispensable as the risk of radiation damage is eliminated and instrumentation is more accessible.

\section{Operando isothermal microcalorimetry of electrochemical energy storage}

Isothermal microcalorimetry (IMC) is a non-radiative operando method where heat flow generated by the electrochemical cell is measured at constant temperature. Isothermal microcalorimetry
(IMC) has been employed to investigate multiple battery systems, including $\mathrm{Li} / \mathrm{Si}, \mathrm{Li} / \mathrm{LiNi}_{0.8} \mathrm{Mn}_{0.1} \mathrm{Co}_{0.1} \mathrm{O}_{2}$ (NMC811), graphite/ $\mathrm{LiCoO}_{2}$, and $\mathrm{Li} / \mathrm{Li}_{2} \mathrm{Ru}_{0.75} \mathrm{Sn}_{0.25} \mathrm{O}_{3}$ [2-5].

Generally, the energy balance of a battery is expressed as: [6]

$$
\dot{Q}=C_{\mathrm{p}} \frac{\mathrm{d} T}{\mathrm{~d} t}+\dot{q}
$$

where $\mathrm{C}_{\mathrm{p}}, \dot{Q}$, and $\dot{q}$ are the heat capacity, the rate of heat generated from an active cell, and the rate of heat dissipation from a battery to ambient conditions, respectively. The heat generated from an electrochemical cell under the passage of current leads to a local temperature change, which dissipates to its surroundings. In calorimetry, the thermal flux measured by the instrument represents the heat dissipation from the cell through the heat transfer media (i.e., air, oil etc.). In an isothermal microcalorimeter (IMC) heat flow is monitored at constant temperature; therefore, the capacitive heat $\left(C_{\mathrm{p}} \frac{\mathrm{d} T}{\mathrm{~d} t}\right)$ and the heat transfer coefficients $\left(h=\frac{\dot{q}}{A(\Delta T)}\right)$ associated with heat transfer media are neglected. Thus, the rate of heat (referred as "heat flow" herein) dissipated from the cell $(\dot{q})$ represents total heat flow generated by the cell $(\dot{Q})$ in IMC experiments.

Precedent literature has described theoretically and shown experimentally that the total heat flow measured by the IMC is composed of three predominate sources of heat generation: (1) polarization, (2) entropy, and (3) parasitic reactions (Fig. 1) [7-9]. Thus, total heat flow of a battery $(\dot{Q})$ under isothermal conditions is the summation of the polarization $\left[I\left(E-E_{\mathrm{eq}}\right)\right]$, entropic $\left[I T\left(\frac{\mathrm{d} E_{\mathrm{eq}}}{\mathrm{d} T}\right)\right]$, and parasitic $\left[Q_{\text {parasitic }}\right]$ heat flow contributions (Eq. 2).

$$
\dot{Q}=I\left(E-E_{\mathrm{eq}}\right)+I T\left(\frac{\mathrm{d} E_{\mathrm{eq}}}{\mathrm{d} T}\right)+Q_{\text {parasitic }}
$$

where, $E$ represents the potential of the cell under the passage of current $(I), E_{\text {eq }}$ is the thermodynamic equilibrium potential, $T$ is temperature of the isothermal bath, and $\frac{\mathrm{d} E_{\text {eq }}}{\mathrm{d} T}$ is the equilibrium potential-temperature coefficient. Polarization heat flow arises from any processes that causes the delivered potential to deviate from the cells equilibrium potential at a given lithiation state. The polarization of an electrochemical cell encompasses ohmic, activation, and concentration polarizations [10]. Entropic heat flow arises from entropy change due to the structural disorder in the system, including sources of configurational entropy, phonon entropy, and electronic entropy [11]. The phonon entropy and electronic entropy are associated with lattice vibration and thermal disorder of the near-Fermi electron state, respectively. The configurational entropy originates from the disorder of $\mathrm{Li}$ atom placing vacancies, which is regarded as the dominant factor of the cell's entropy change [12]. Parasitic heat flow is attributed to parasitic reactions, which include electrolyte decomposition and SEI formation. By measuring heat flow generated upon 


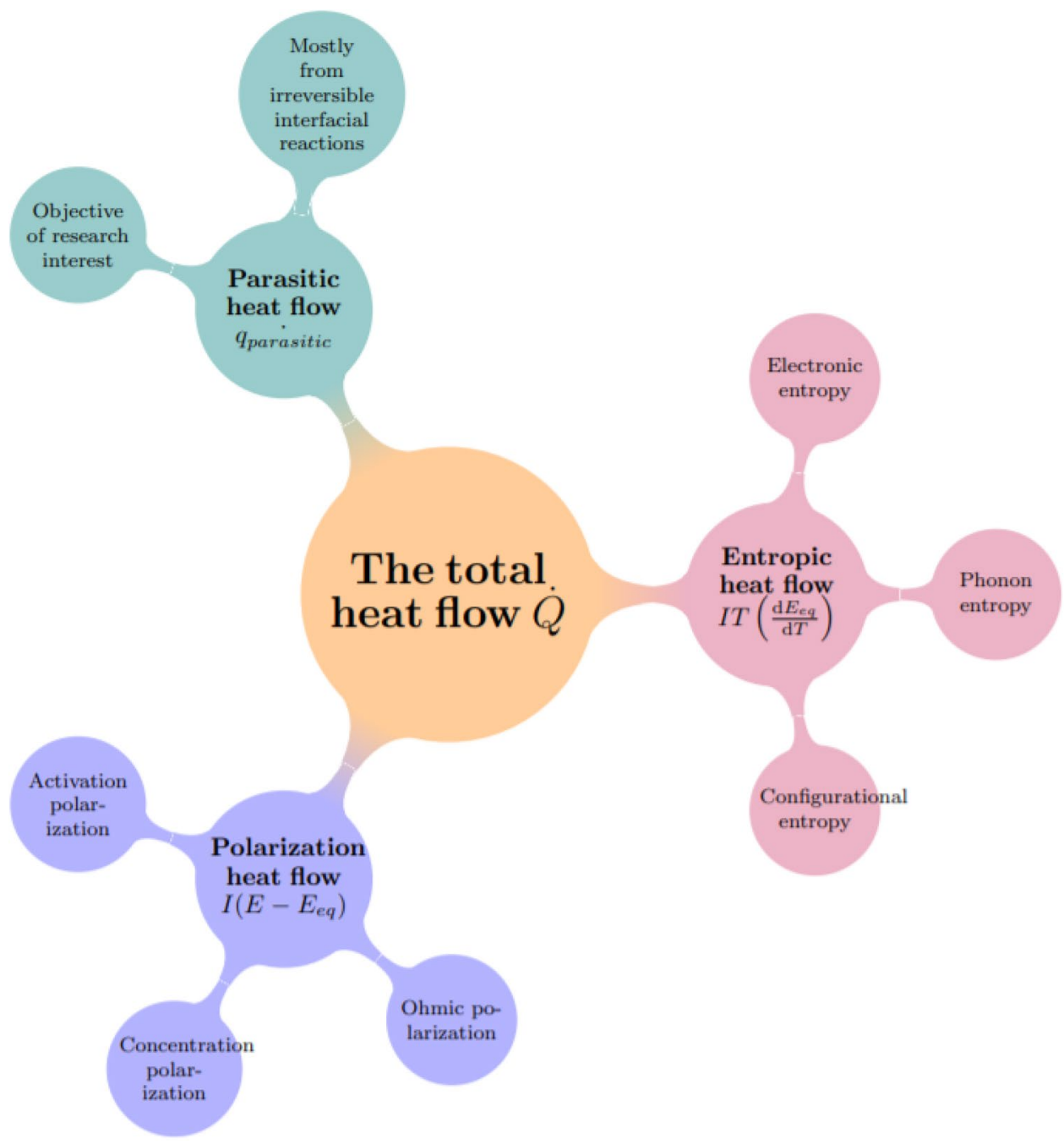

Figure 1: Heat flow sources in a cycling battery.

battery cycling, further insight into the reaction kinetics can be obtained by understanding the electrode material, evaluating the onset or evolution of parasitic reactions, and assessing the (electro)chemical reactions that occur.

\section{Bulk and interfacial operando characterization of conversion materials}

The need for operando characterization is pressing as many battery chemistries with superior energy densities operate via more complex, conversion mechanisms rather than traditional intercalation processes. During a conversion reaction, electron transfer and ion transport cause the changes in the electrode material structure. These structural changes can be severe and irreversible, often resulting in significant volume expansion and particle fracture limiting capacity retention. Additionally, solid electrolyte interphase (SEI) formation and evolution on conversion electrodes is more complex. Controlled formation of SEI is critical and occurs when a non-aqueous liquid electrolyte decomposes on the solid electrode surface $[13,14]$. An SEI of appropriate thickness can protect the electrode from side reactions (i.e., dissolution), thereby, extending cycle life. However, for conversion electrodes, structural and volumetric changes can lead to SEI instability, where new active sites for electrolyte reduction are continuously exposed in each cycle $[15,16]$. Continuous decomposition of electrolyte consumes lithium ions and solvent, increases SEI layer thickness, and limits ionic and electronic transport resulting in capacity loss $[17,18]$. Notably, few techniques can dynamically characterize the formation and evolution of the SEI, as the layer is thin $(<100 \mathrm{~nm})$, amorphous, and sensitive to air/moisture [19]. Therefore, interfacial operando characterization of conversion materials, in addition to operando bulk characterization, is of the upmost importance for developing innovative electrochemical energy storage systems with higher energy densities. 

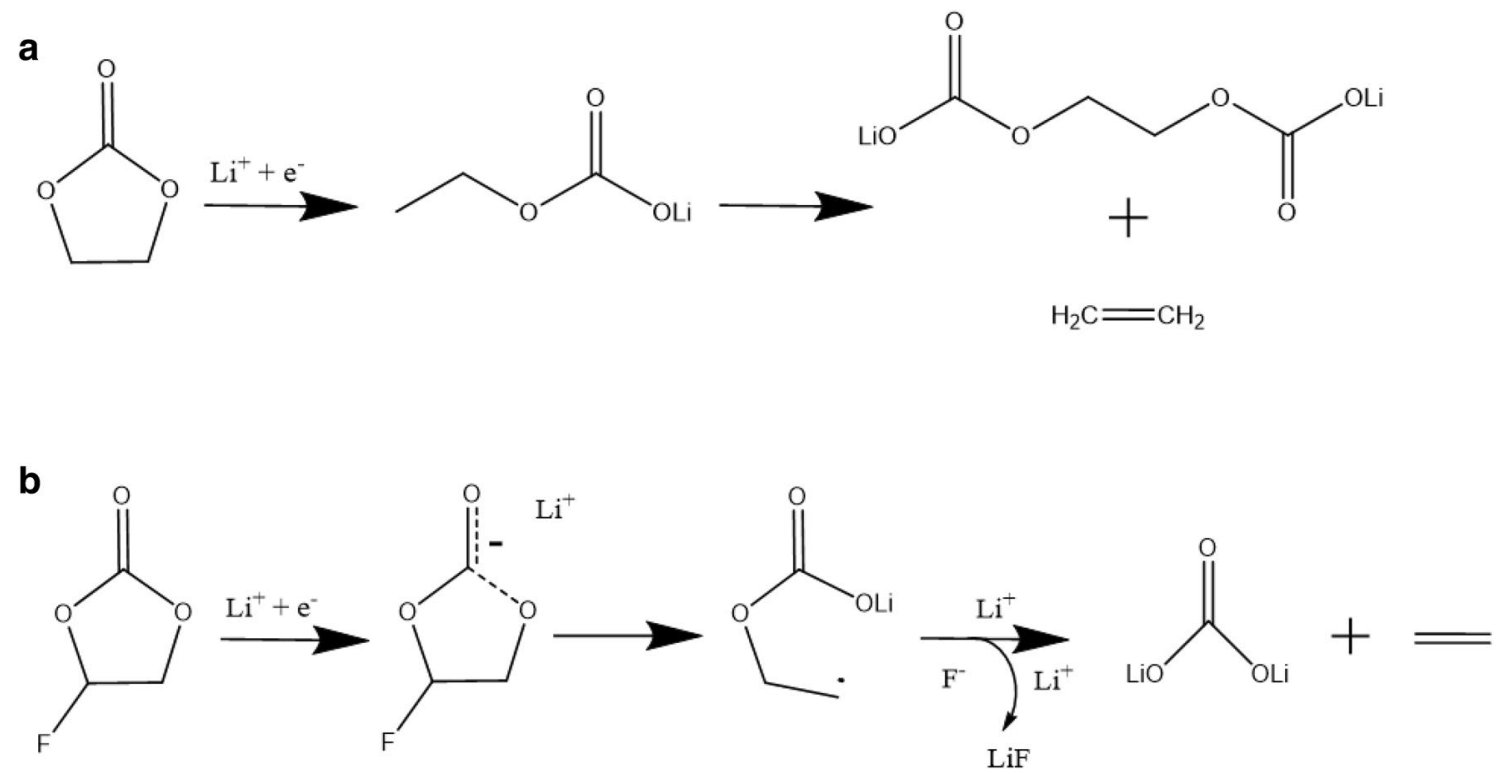

Figure 2: The reduction of (a) EC and (b) FEC exhibiting the different products formed contributing to variations in the SEl on conversion electrodes.

\section{Electrolyte modification for SEI stability on conversion electrodes}

The stability of the SEI on conversion anode materials can be improved by using an electrolyte additive or co-solvent. While ethylene carbonate (EC) is commonly used in lithium-ion battery electrolytes, fluoroethylene carbonate (FEC) is a well explored electrolyte additive. The addition of the fluorine group to the cyclic alkyl ester reduces the energy of the lowest unoccupied molecular orbital (LUMO), enabling FEC to reduce at higher potentials $(\sim 1.1-2 \mathrm{~V})$ [20] relative to the non-fluorinated ethylene carbonate (EC) analog (below $1 \mathrm{~V}$ ) [20, 21]. EC reduction results in the generation of insoluble lithium carbonates and organic species (Fig. 2a), which can increase electrolyte and overall cell resistance $[22,23]$. The overall reduction of FEC yields a metastable FEC anion that further facilitates radical polymerization (Fig. 2b) [24, 25]. The elastomeric structure in the initial SEI layer formed through the recombination of radical polymerization [26] can adjust to accommodate the significant volume expansion that the electrode undergoes during lithiation, therefore, resulting in improved cycle life. The production of such fluorinated SEI species $(\mathrm{LiF})$ facilitates $\mathrm{Li}^{+}$ion transport and reduces the charge-transfer resistance at the electrode/electrolyte interface [27]. Thus, FEC has been shown to generate a denser, homogenously-distributed, low resistance, and more elastic SEI, which improves cycle life of conversion and alloying anodes $[5,28]$. The electrochemical benefits of FEC and subsequent SEI modifications have been experimentally observed in lithium-ion batteries with silicon [26-35] and transition metal anodes [36, 37].

\section{Magnetite $\left(\mathrm{Fe}_{3} \mathrm{O}_{4}\right)$ : a model insertion-conversion electrode material}

Magnetite $\left(\mathrm{Fe}_{3} \mathrm{O}_{4}\right)$ is a model anode material for understanding insertion and conversion reactions as it undergoes both processes electrochemically. Abundant in nature, $\mathrm{Fe}_{3} \mathrm{O}_{4}$ can theoretically deliver eight electrons per formula unit, resulting in a high theoretical specific capacity $(924 \mathrm{mAh} / \mathrm{g})$. The redox active centers, consist of $\mathrm{Fe}^{3+}$ and $\mathrm{Fe}^{2+}$ and occupy both tetrahedral (8a) and octahedral (16d) sites within a cubic close-packed (ccp) oxygen anion framework to form an inverse spinel structure [38]. During lithiation, $\mathrm{Li}^{+}$ions intercalate into octahedral sites, iron cations then migrate to form a rock-salt-like phase before finally converting to nanosized $\mathrm{Fe}^{0}$ and $\mathrm{Li}_{2} \mathrm{O}$, Eqs. 3-7 [39].

(1) The first $\mathrm{Li}^{+}$equivalent intercalates into an interstitial octahedral (16c) site

$$
(\mathrm{Fe})_{8 a}\left(\mathrm{Fe}_{2}\right)_{16 d} \mathrm{O}_{4}+\mathrm{Li}^{+}+e^{-} \rightarrow(\mathrm{LiFe})_{16 c}\left(\mathrm{Fe}_{2}\right)_{16 d} \mathrm{O}_{4}
$$

(2) The second $\mathrm{Li}^{+}$equivalent inserts into the $\mathrm{Fe}_{3} \mathrm{O}_{4}$ lattice, displacing the $\mathrm{Li}^{+}$located in the $16 \mathrm{c}$ site. The two $\mathrm{Li}^{+}$ redistribute between $8 \mathrm{a}, 48 \mathrm{f}$, and $8 \mathrm{~b}$ interstitial tetrahedral sites

$(\mathrm{LiFe})_{16 c}\left(\mathrm{Fe}_{2}\right)_{16 d} \mathrm{O}_{4}+\mathrm{Li}^{+}+e^{-} \rightarrow\left(\mathrm{Li}_{2}\right)_{8 a / 48 f / 8 b}\left(\mathrm{Fe}_{3}\right)_{16 c / 16 d} \mathrm{O}_{4}$

(3) The third and fourth $\mathrm{Li}^{+}$equivalents result in a conversion to $\mathrm{Li}_{2} \mathrm{O} \cdot \mathrm{FeO}$ and $\mathrm{Fe}^{0}$ metal composites

$\left(\mathrm{Li}_{2}\right)_{8 a / 48 f / 8 b}\left(\mathrm{Fe}_{3}\right)_{16 c / 16 d} \mathrm{O}_{4}+2 \mathrm{Li}^{+}+2 e^{-} \rightarrow 2 \mathrm{Li}_{2} \mathrm{O} \cdot \mathrm{FeO}+\mathrm{Fe}^{0}$

(4) Reaction of the final four $\mathrm{Li}^{+}$equivalents result in $\mathrm{Fe}^{0}$ metal and $\mathrm{Li}_{2} \mathrm{O}$ 


$$
2 \mathrm{FeO}+4 \mathrm{Li}^{+}+4 e^{-} \rightarrow 2 \mathrm{Li}_{2} \mathrm{O}+2 \mathrm{Fe}^{0}
$$

The overall lithiation reaction for $\mathrm{Fe}_{3} \mathrm{O}_{4}$ is

$$
\mathrm{Fe}_{3} \mathrm{O}_{4}+8 \mathrm{Li}^{+}+8 e^{-} \rightarrow 3 \mathrm{Fe}^{0}+4 \mathrm{Li}_{2} \mathrm{O}
$$

The application of $\mathrm{Fe}_{3} \mathrm{O}_{4}$ as an anode material is limited by poor capacity retention associated with significant volume expansion resulting from phase changes during cycling and the repetitive formation of an unstable solid electrolyte interphase (SEI) $[17,18,39]$. FEC has been shown to improve cycle life of $\mathrm{Fe}_{3} \mathrm{O}_{4}$ cells by modifying the SEI layer [16, 40, 41]. For example, $\mathrm{Li} / \mathrm{Fe}_{3} \mathrm{O}_{4}$ cells with $1.33 \mathrm{M}$ FEC demonstrated a $280 \%$ increase in delivered capacity relative to non-FEC cells after 100 cycles [20]. X-ray photoelectron spectroscopy (XPS) characterization of $\mathrm{Fe}_{3} \mathrm{O}_{4}$ electrodes after lithiation in the presence of FEC [1 M $\mathrm{LiPF}_{6}$ 30:70 FEC/dimethyl carbonate (DMC)] and EC [1 M $\mathrm{LiPF}_{6}$ 30:70 EC/DMC] electrolyte showed increased LiF content in the SEI layer after lithiation with FEC, consistent with reductive decomposition of FEC and thermal decomposition of the $\mathrm{LiPF}_{6}$ salt [16]. In addition, the $\mathrm{Fe}_{3} \mathrm{O}_{4}$ electrodes lithiated with FEC showed a decrease in inorganic and organic carbonate species relative to EC, suggesting presence of an elastomeric, cross-linked polymer product or in-situ $\mathrm{CO}_{2}$ formation [16]. Operando atomic force microscopy (AFM) also showed FEC electrolyte produces a denser SEI layer compared to EC electrolyte on $\mathrm{Fe}_{3} \mathrm{O}_{4}$ thin film electrodes during cyclic voltammetry testing [41].

\section{Operando bulk and interfacial characterization of $\mathrm{Fe}_{3} \mathrm{O}_{4}$ : an IMC and XAS approach}

Herein we apply operando IMC and XAS to characterize bulk and interfacial changes of $\mathrm{Fe}_{3} \mathrm{O}_{4}$ during lithiation in the presence of EC [1 $\mathrm{M} \mathrm{LiPF}_{6}$ EC/DMC (3:7)] and FEC [1 $\mathrm{M} \mathrm{LiPF}_{6}$ FEC/ DMC (3:7)]. The $\mathrm{Fe}_{3} \mathrm{O}_{4}$ crystallite size was controlled via coprecipitation synthesis $[42,43]$, and characterized via XRD and TEM. In electrodes, the size of the active material will significantly govern the area and morphology of the interface. Intuitively, electrodes packed with finer or porous-structured active materials could have a larger contact area with the electrolyte. On one hand, this increased contact facilitates the ion transport; yet on the other hand, enlarged electrolyte-electrode interaction area results in more interfacial parasitic reactions. Therefore, controlling the parameter of size is critical for our study in order to accurately quantify the different interfacial parasitic reaction mechanisms introduced solely by the electrolyte solvents. Mechanisms associated with parasitic reactions that contribute to non-reversible capacity loss were evaluated by IMC. Chemical and structural differences produced through the incorporation of a fluorinated species within the electrolyte were evaluated by analysis of the X-ray absorption near edge structure (XANES) and extended X-ray absorption fine structure (EXAFS) regions of the operando XAS spectra. Thus when employed in concert, IMC and XAS are shown to be effective and complementary tools for understanding interfacial parasitic reactions, including SEI formation operando providing comprehensive understanding of electrolyte impact on the electrochemical $\mathrm{Fe}_{3} \mathrm{O}_{4}$ conversion process.

\section{Results and discussion}

\section{Materials characterization}

$\mathrm{X}$-ray diffraction (XRD) and transmission electron microscopy were employed to characterize the as-synthesized $\mathrm{Fe}_{3} \mathrm{O}_{4}$ nanopowder. The inverse spinel structure was confirmed via Rietveld refinement (Fig. 3a; Table S1). A crystallite size of $11 \pm 1 \mathrm{~nm}$ calculated from the (220) peak using the Scherrer equation was comparable to the refinement derived crystallite size of $\sim 14 \mathrm{~nm}$. TEM images demonstrate that the $\mathrm{Fe}_{3} \mathrm{O}_{4}$ material consists of spherical particles (Fig. 3b). Particle size estimates from the TEM images demonstrate a minimum particle size of $3 \mathrm{~nm}$, maximum of $18 \mathrm{~nm}$, and an average particle size of $10 \mathrm{~nm}$ (Fig. 3c).

\section{Operando isothermal microcalorimetry (IMC)}

The voltage and heat flow profiles for the first lithiation of $\mathrm{Li} /$ $\mathrm{Fe}_{3} \mathrm{O}_{4}$ cells with $1 \mathrm{M} \mathrm{LiPF}_{6}$ EC/DMC (3/7 v/v) and $1 \mathrm{M} \mathrm{LiPF}_{6}$ FEC/DMC (3/7 v/v) electrolyte are shown in Fig. 4 with duplicate experiments presented in Figure S1. From the lithiation mechanism of $\mathrm{Fe}_{3} \mathrm{O}_{4}$ (Eq. 5), changes in enthalpy $\left(\Delta \mathrm{H}_{\mathrm{rxn}}\right)$, entropy $\left(\Delta \mathrm{S}_{\mathrm{rxn}}\right)$ and Gibbs free energy $\left(\Delta \mathrm{G}_{\mathrm{rxn}}\right)$ were estimated using standard heats of formation $\left(\mathrm{H}_{\mathrm{f}}\right)$ and standard entropies $\left(\mathrm{S}_{\mathrm{f}}\right)$ of $\mathrm{Fe}_{3} \mathrm{O}_{4(\mathrm{~s})}, \mathrm{Fe}_{(\mathrm{s})}, \mathrm{Li}_{(\mathrm{s})}$, and $\mathrm{Li}_{2} \mathrm{O}_{(\mathrm{s})}$ (Table S2) [44]. For an eight electron equivalent reduction of $\mathrm{Fe}_{3} \mathrm{O}_{4}$, thermodynamic considerations estimate a release of $\sim 5300 \mathrm{~J} / \mathrm{g}$ of heat. The energy released from the $\mathrm{Li} / \mathrm{Fe}_{3} \mathrm{O}_{4}$ cells $(\Delta E)$ measured in Fig. $4 \mathrm{a}$, b was calculated by summing the electrical work $(W)$ and the total heat measured by the microcalorimeter $(Q)$. Electrical work was determined by integrating the cell potential with respect to specific capacity, whereas the total heat was determined by integrating the heat flow with respect to time (Table S2). For both the EC and FEC-containing $\mathrm{Li} / \mathrm{Fe}_{3} \mathrm{O}_{4}$ cells, the measured energy change $(\Delta E)$ exceeds the theoretical value of thermodynamic Gibbs energy change $\left(\Delta G_{\mathrm{rxn}}\right)$ (Eq. 5; Table S2), indicating electrochemical kinetics under a loaded current also contributes to the heat output. Even at a moderate rate of discharge, electrochemical lithiation does not coincide with a thermodynamic equilibrium state, especially in conversion-type electrode materials whose kinetic resistance can be significant. As a result, the 

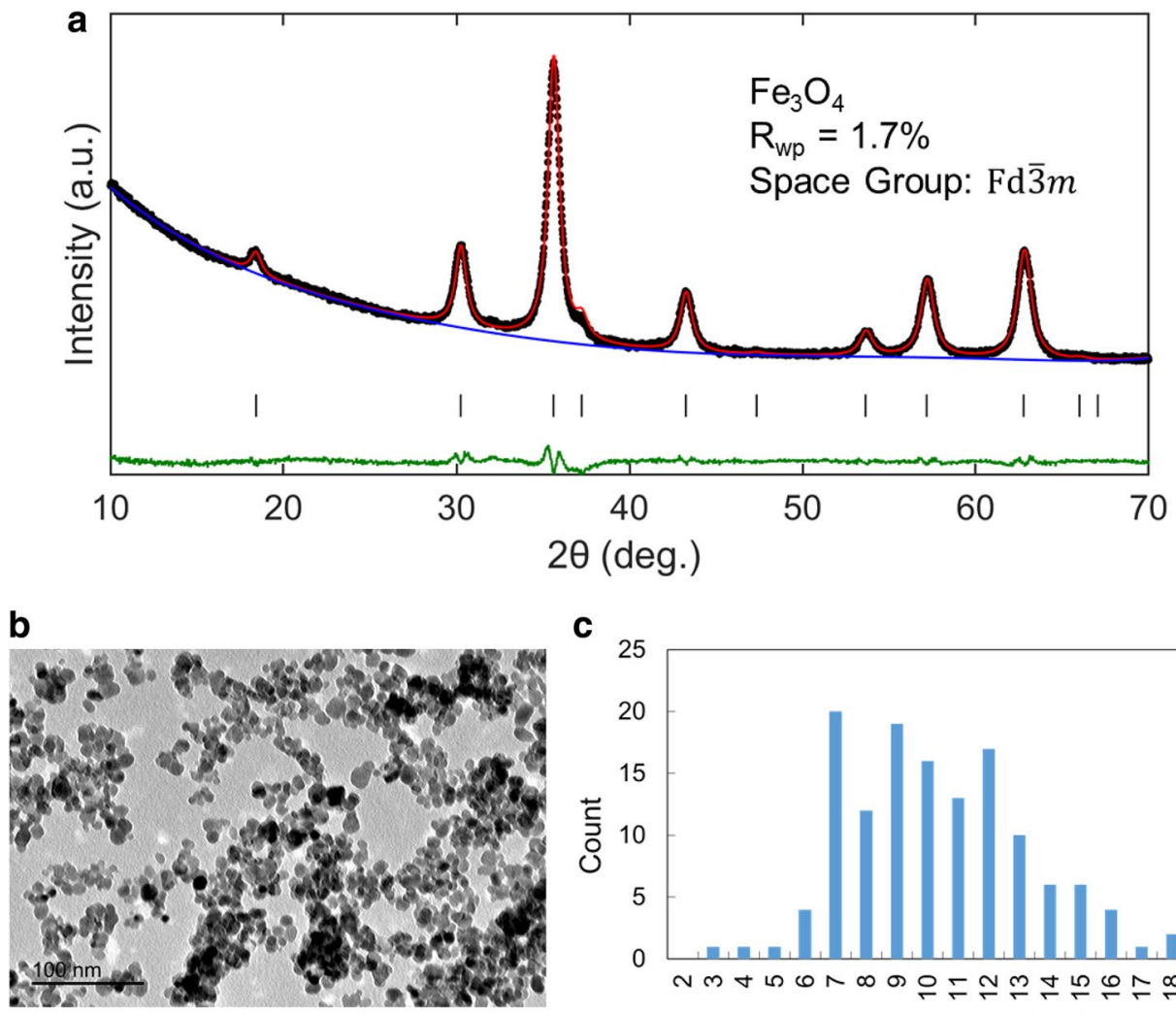

C

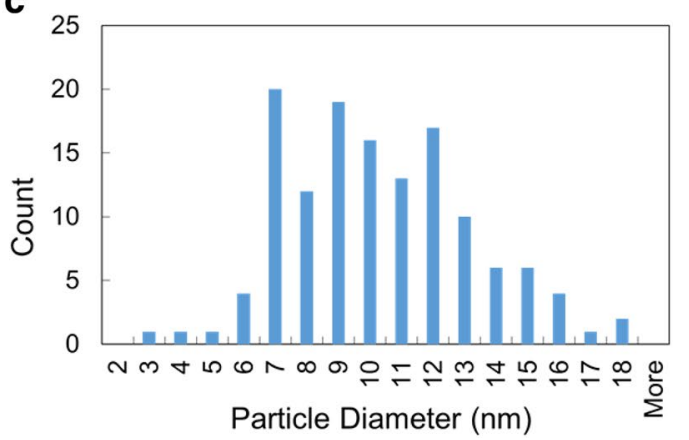

Figure 3: Characterization of $\mathrm{Fe}_{3} \mathrm{O}_{4}$ nanopowder. (a) Rietveld refinement of the XRD pattern with reflection lines. Black represents the observed pattern, red is the calculated fit, green is the difference, and blue represents background. (b) TEM image and c particle size distribution statistics.
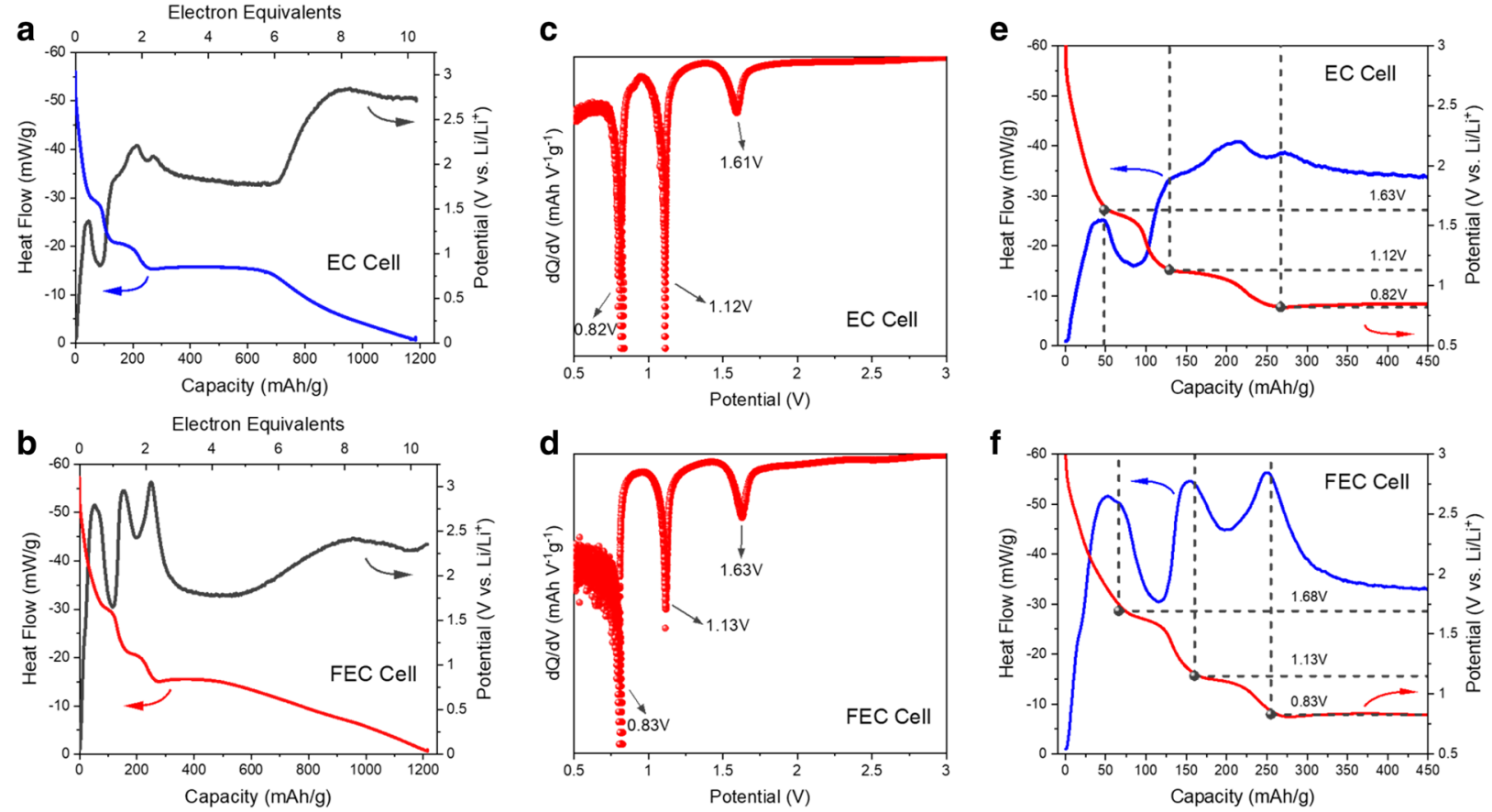

Figure 4: First lithiation voltage and heat flow profiles for $\mathrm{Li} / \mathrm{Fe}_{3} \mathrm{O}_{4}$ cells containing (a) $1 \mathrm{M} \mathrm{LiPF} 6 \mathrm{EC} / \mathrm{DMC}(3 / 7 \mathrm{v} / \mathrm{v}$ ) and (b) $1 \mathrm{M} \mathrm{LiPF} 6 \mathrm{FEC} / \mathrm{DMC}$ (3/7 v/v) electrolyte. *Negative heat flow represents an exothermic process. First lithiation (c) and (d) differential capacity and (e) and (f) heat flow profiles of EC and FEC-containing cells, respectively. 
actual energy change in electrochemical processes considering kinetic factors should be more than the predicted $\Delta \mathrm{G}_{\mathrm{rxn}}$ solely from chemical thermodynamics.

The heat flow and electrochemistry profiles for $\mathrm{Li} / \mathrm{Fe}_{3} \mathrm{O}_{4}$ cells with $1 \mathrm{M} \mathrm{LiPF}_{6}$ EC/DMC (3/7 v/v) are provided in Fig. 4a. The first distinctive heat flow peak occurs at $\sim 48 \mathrm{mAh} / \mathrm{g}(1.63 \mathrm{~V})$, corresponds the onset of a two-phase region where $\mathrm{Fe}_{3} \mathrm{O}_{4}$ and $(\mathrm{LiFe})_{16 \mathrm{c}}\left(\mathrm{Fe}_{2}\right) 16_{\mathrm{d}} \mathrm{O}_{4}$ coexist. From the beginning of lithiation to the end of the first discharge (lithiation) plateau, one $\mathrm{Li}^{+}$equivalent inserts into the octahedral $16 \mathrm{c}$ sites in the inverse spinel structure and tetrahedral $(\mathrm{Fe})_{8 \mathrm{a}}$ also migrate to octahedral $16 \mathrm{c}$ sites (Eq. 1). The second heat flow peak located at $\sim 130 \mathrm{mAh} / \mathrm{g}$ $(1.13 \mathrm{~V})$, suggests the coexistence of $(\mathrm{LiFe})_{16 \mathrm{c}}\left(\mathrm{Fe}_{2}\right) 16_{\mathrm{d}} \mathrm{O}_{4}$ and $\left(\mathrm{Li}_{2}\right)_{8 \mathrm{a} / 48 \mathrm{f} / 8 \mathrm{~b}}\left(\mathrm{Fe}_{3}\right)_{16 \mathrm{c} / 16 \mathrm{~d}} \mathrm{O}_{4}$. Upon the transition shown in Eq. 2, $\mathrm{Li}^{+}$located in octahedral $16 \mathrm{c}$ sites redistribute to tetrahedral sites $(8 \mathrm{a} / 48 \mathrm{f} / 8 \mathrm{~b})$. The redistribution of $\mathrm{Li}^{+}$enables additional tetrahedral $(\mathrm{Fe})_{8 \mathrm{a}}$ to migrate to octahedral positions. The third heat flow inflection appears at the onset of a discharge plateau of $0.82 \mathrm{~V}(267 \mathrm{mAh} / \mathrm{g})$, where a new phase $(\mathrm{FeO})$ exists in the system. The conversion reaction to rock-salt $\mathrm{FeO}$ is shown in Eq. 3 . The cell lithiated with FEC electrolyte (Fig. 4b) demonstrates three distinctive peaks at $\sim 60 \mathrm{mAh} / \mathrm{g}(1.68 \mathrm{~V}), 160 \mathrm{mAh} / \mathrm{g}$ (1.13 V), and $255 \mathrm{mAh} / \mathrm{g}(0.83 \mathrm{~V})$.

Analysis of differential capacity $(\mathrm{d} Q / \mathrm{d} V)$ plots (Fig. $4 \mathrm{c}$, d) in relation to the heat flow profiles (Fig. 4e, f) indicates a consistent lithiation mechanism of $\mathrm{Fe}_{3} \mathrm{O}_{4}$ in the FEC and EC containing cells. The EC (Fig. 4c) and FEC (Fig. 4d) differential capacity profiles show three distinctive peaks in the potential window of $0.5-3.0 \mathrm{~V}$ (vs $\mathrm{Li} / \mathrm{Li}^{+}$). Peaks in $\mathrm{dQ} / \mathrm{dV}$ profiles indicate phase transitions upon early-stage $\mathrm{Fe}_{3} \mathrm{O}_{4}$ lithiation as shown in Eqs. 3-5. Interestingly, heat flow peaks in both EC (Fig. 4e) and FEC (Fig. 4f) heat flow profiles are also observed at the same lithiation states where differential capacity peaks and discharge plateaus appear, suggesting real-time heat flow can indicate phase transitions in electroactive materials and structural changes account for a part of thermal output released from the $\mathrm{Li} / \mathrm{Fe}_{3} \mathrm{O}_{4}$ cells.

Notably, the initial insertion reactions and beginning of the $\mathrm{FeO}$ conversion reaction occur at higher potentials and deliver greater capacities when FEC electrolyte is present. Additionally, the magnitude of the heat flow at these transition points are larger in the FEC than the EC cell. For example, the maximum heat flow for the FEC cell is $-56 \mathrm{~mW} / \mathrm{g}$, compared to $-40 \mathrm{~mW} / \mathrm{g}$ for the EC cell. The differences in heat flow between EC and FEC cells early in the first lithiation suggest differences in electrolyte reactivity [20].

Moreover, the difference in heat generation between EC and FEC cells arises predominately at the early lithiation state (0-400 mAh/g), shown by Table S3. The total heat is calculated by integrating the heat flow curve measured by the IMC. Before $400 \mathrm{mAh} / \mathrm{g}$, the EC cell releases $-312.3 \mathrm{mWh} / \mathrm{g}$ of heat, which is $\sim 25 \%$ less than the FEC cell $(-413.6 \mathrm{mWh} / \mathrm{g})$. In contrast, the total heat dissipated during the first lithiation to $0.03 \mathrm{~V}$ and after $400 \mathrm{mAh} / \mathrm{g}$ of lithiation is comparable between the FEC and EC cells. Similar trends are observed when total heat is normalized to capacity (normalized heat). Early in lithiation, the FEC cell exhibits greater normalized heat, whereas throughout and at the end of the first lithiation, normalized heats among EC and FEC cells are comparable (Table S3).

Moreover, both the EC and FEC cells experience the largest normalized heat during cycle 1 lithiation relative to cycle 1 delithiation and cycle 2 (Figure S2, Figure S3, Table S4). During cycle 1 delithiation, the EC and FEC cells deliver 575 and 473 $\mathrm{mAh} / \mathrm{g}$, corresponding to a total heat generation of 230.3 and $176.2 \mathrm{mWh} / \mathrm{g}$, respectively. In cycle 2 , the EC cell produces total heats of 365.1 and $156.1 \mathrm{mWh} / \mathrm{g}$, reaching lithiation and delithiation capacities of $691 \mathrm{mAh} / \mathrm{g}$ and $341 \mathrm{mAh} / \mathrm{g}$, respectively. In cycle 2, the FEC cell generates slightly less heat during lithiation (225.4 mWh/g) and delithiation (103.8 mWh/g), consistent with lower capacities of $492 \mathrm{mAh} / \mathrm{g}$ and $243 \mathrm{mAh} / \mathrm{g}$ for lithiation and delithiation, respectively. The consistency between capacity and heat generation during cycle 1 delithiation and cycle 2 (de) lithiation further indicates that the significant differences among the EC and FEC cells occur during the first lithiation before 400 $\mathrm{mAh} / \mathrm{g}$ of lithiation.

\section{Polarization and entropy}

Polarization and entropic heat flow contributions were determined using Galvanostatic intermittent titration technique (GITT) and potential-temperature measurements (Fig. 5, Figure S4). The specific capacity of the GITT tests were normalized to the IMC cell by equalizing capacities at the lithiation voltage limit of $0.03 \mathrm{~V}$ (Figure S5). In both EC (Fig. 5a) and FEC (Fig. 5b) cells, the polarization heat flow is the major heat flow source compared to the entropic contribution. The polarization and entropic heat flow contributions are most distinct between the EC and FEC cells before two molar electron equivalents of lithiation $(<2 \mathrm{ee})$, consistent with total heat flow measurements (Fig. 3) and total heat calculations (Table S3). From 0 to 2 ee, the FEC cell exhibits larger polarization heat flow $\sim 40$ $\mathrm{mW} / \mathrm{g}$, whereas the EC cell shows polarization heat flow range between $\sim 15 \mathrm{~mW} / \mathrm{g}$ to $\sim 30 \mathrm{~mW} / \mathrm{g}$. The higher initial polarization in FEC cells before 2 ee is surprising, as FEC is proposed to reduce resistance at the electrode interface through stable SEI formation [27]. The IMC data indicate that in this lithiation regime, a stable SEI has not yet formed on the electrode surface.

\section{Parasitic heat flow contribution}

Polarization and entropic heat flow components were summed and compared with the total heat flow measured by the IMC 
a
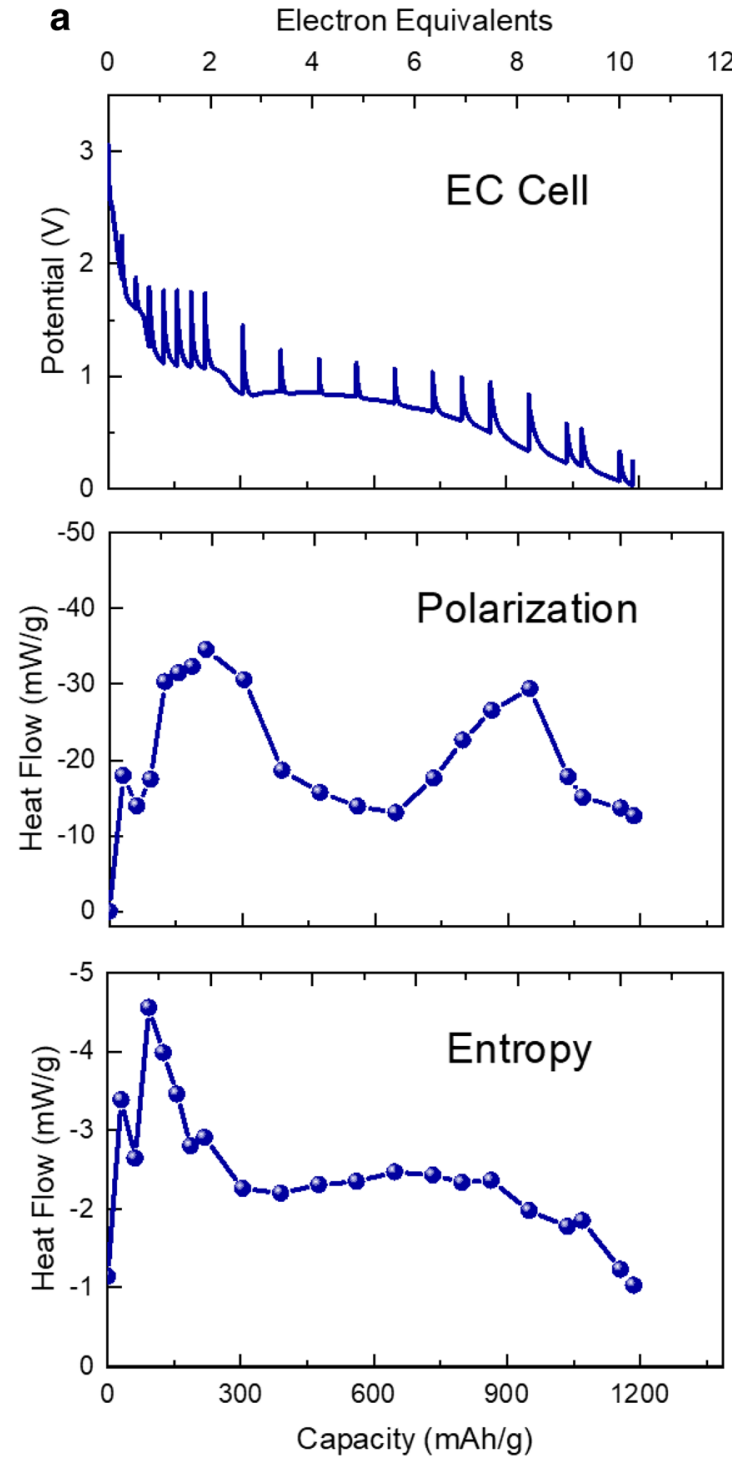

b Electron Equivalents
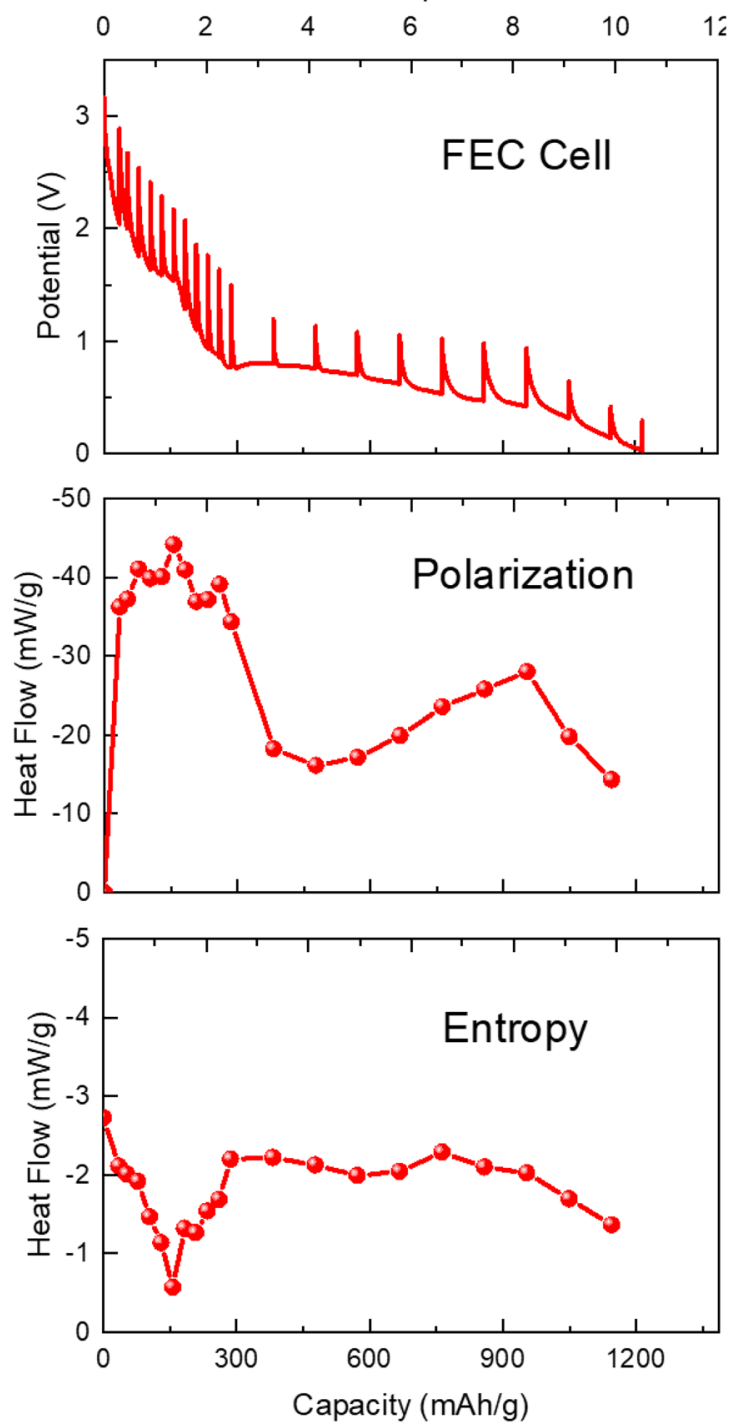

Figure 5: The voltage profile of the GITT, polarization, and entropic heat flows of (a) FEC cell and (b) EC cell.

a

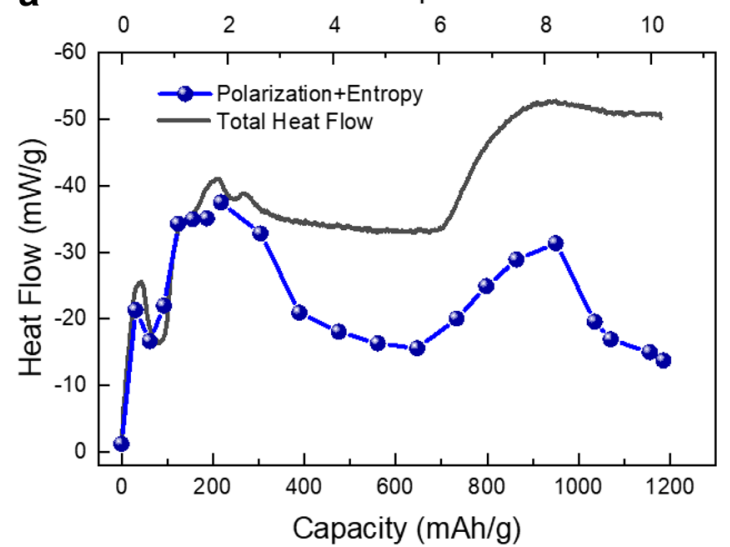

b

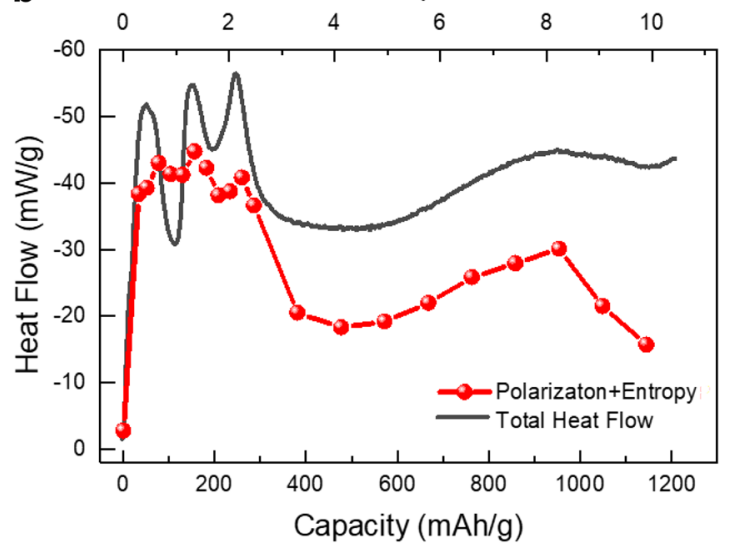

Figure 6: Comparison of total heat flow from IMC (gray, solid line) and experimentally determined polarization and entropic heat flow contributions during lithiation in the presence of (a) 1 M LiPF6 EC/DMC (3/7 v/v) (blue, connected-dot line) and (b) 1 M LiPF6 FEC/DMC (3/7 v/v) (red, connected-dot line). 
(Fig. 6). The difference between the polarization and entropic heat flow and total heat flow curves represents parasitic heat flow. Before 2 ee, the sum of entropic and polarization heat flow contributions matches the total heat flow (Fig. 6a) for the EC cell consistent with previous reports, suggesting that interfacial parasitic reactions are not a significant factor as polarization and entropic heat flow fully capture and describe all heat generated. The two curves begin to deviate after 2 ee of lithiation $(\sim 0.9 \mathrm{~V})$, indicating the onset of parasitic reactions. The separation of two curves increases upon the lithiation after 2 ee, suggesting continuous reduction of electrolyte co-solvents and the formation of the SEI. Parasitic heat flow in the EC cell becomes a major contributor $(\sim 80 \%)$ to the observable heat flow at the end of lithiation.

For the FEC cell (Fig. 6b), total heat flow is $\sim 20 \mathrm{~mW} / \mathrm{g}$ greater than the polarization and entropic heat flow contributions before 2 ee of lithiation, indicating earlier onset of the parasitic reactions relative to $\mathrm{EC}$, which is consistent with reports indicating FEC reduction and SEI formation occurs at higher potential $[5,33]$. After 2 ee, total heat flow remains higher than the polarization and entropic heat flow curve indicating parasitic reactions continue to evolve in the presence of FEC during lithiation.

Heat generated by polarization and entropy was calculated by integrating the polarization and entropic heat flow curve over time (Table S5). The polarization and entropic heat were subtracted from total heat calculated in Table S3 to quantify the parasitic heat contribution. The greatest difference in parasitic heat generation occurs before 2 ee of lithiation, where parasitic heat contributes to $3 \%$ and $10 \%$ of total heat flow for the EC and FEC cells, respectively. Moreover, before $400 \mathrm{mAh} / \mathrm{g}$ of lithiation, $17 \%$ of total heat generated by the FEC cell is associated with parasitic contribution, in contrast to $12 \%$ for the EC cell. The greater parasitic heat generation observed for the FEC cell early in the lithiation is consistent with greater interfacial reactively. Taking into account the entirety of the first lithiation, parasitic heat accounts for $40 \%$ and $36 \%$ of total heat generated by the EC and FEC cells, respectively suggesting parasitic heat accounts for more of the total heat in the $\mathrm{EC}$ condition at the end of lithiation. The dominance of parasitic heat generation at the end of lithiation for the EC cell is confirmed by quantifying parasitic heat $>400 \mathrm{mAh} / \mathrm{g}$, where $51 \%$ of total heat is attributed to parasitic reactions relative to $46 \%$ for the EC cell.

\section{Operando X-ray absorption spectroscopy (XAS)}

Operando XAS was collected during lithiation of in-situ Li/ $\mathrm{Fe}_{3} \mathrm{O}_{4}$ cells at $115 \mathrm{~mA} / \mathrm{g}$ with either EC or FEC electrolyte to discriminate bulk changes in the Fe oxidation state reduction and local atomic structure from the X-ray absorption near edge fine structure (XANES) and extended X-ray absorption fine structure (EXAFS), respectively. During the first 2 ee lithiation, the Fe K-edge shifts from $7126.5 \mathrm{eV}$ to $7124.0 \mathrm{eV}$ for both the EC (Fig. 7a) and FEC (Fig. 7d) cells, indicating a reduction of $\mathrm{Fe}^{3+}$ to $\mathrm{Fe}^{2+}$. Additionally, a notable change in the pre-edge feature is observed. $\mathrm{Fe}_{3} \mathrm{O}_{4}$ has a characteristic pre-edge feature associated with $\mathrm{Fe}^{3+}$ tetrahedral atoms. Upon reduction, the pre-edge feature decreases in intensity and the peak broadens, signifying a migration of $\mathrm{Fe}$ from tetrahedral to octahedral sites (Figure S6). These changes in edge energy and pre-edge feature are observed from 0 to 2 ee for both the EC (Fig. 7b) and FEC (Fig. 7e) cells. From 2.1 to 4.0 ee, the pre-edge feature broadens and edge energy remains constant for both the EC (Fig. 7c) and FEC (Fig. 7e) cells.

The edge energy (Fig. 7a) and centroid position of the preedge (Fig. 7b) were tracked to evaluate differences in Fe oxidation state during $\mathrm{Fe}_{3} \mathrm{O}_{4}$ lithiation. A decrease in edge energy and pre-edge centroid position can signify a decrease in Fe oxidation state $[45,46]$. At each electron equivalent, small differences in the edge energy and centroid position are observed $(<0.4 \mathrm{eV})$, suggesting bulk reduction of Fe progresses as a similar rate in both electrolytes, suggesting differences in the voltage profile (Fig. 7c) between the two cells can be attributed to surface phenomena rather than bulk Fe oxidation state changes.

The progression of the EXAFS spectra during the lithiation also suggest bulk changes in the local atomic environment of $\mathrm{Fe}$ are similar in the presence of EC (Fig. 8a, b) and FEC (Fig. 8c, d) electrolyte. The EXAFS spectra of $\mathrm{Fe}_{3} \mathrm{O}_{4}$ have two characteristic peaks attributed to $\mathrm{Fe}-\mathrm{O}$ and $\mathrm{Fe}-\mathrm{Fe}$ interactions. From 0 to 2 ee, the Fe-O peak at $1.4 \AA$ shifts to higher interatomic distances at a similar rate for both the EC and FEC cells (Figure S7). Additionally, the second shell peak near $2.5 \AA$ narrows due to a loss in intensity of the shoulder contribution at $\sim 3.1 \AA$. These observations are consistent with the conversion of $\mathrm{Fe}_{3} \mathrm{O}_{4}$ inverse spinel structure to a FeO-like phase and are supported by EXAFS modeling (Tables S6-S9). From 0 to 1.6 ee, the EXAFS region for both $\mathrm{EC}$ and FEC cells fits the $\mathrm{Fe}_{3} \mathrm{O}_{4}$ inverse spinel structure with good agreement $\left(R_{\text {factor }}<2 \%\right)$. At 1.9 ee, the EXAFS spectra for both FEC and EC cells are best fit with an FeO rock-salt like structure. From 2.1 to 4.0 ee, the EXAFS fits the FeO-like structure and Fe metal is not detected in either cell. Thus, the progression of the EXAFS spectra during lithiation suggests that bulk changes in the Fe atomic environment are not significantly impacted by electrolyte modifications.

\section{Conclusions}

Operando bulk and interfacial characterization provide realtime information on the dynamic processes inside energy storage systems. The acquired information can lead to further electrochemical insights that serve as a catalyst for innovation in energy storage. This article highlights two complimentary 
a
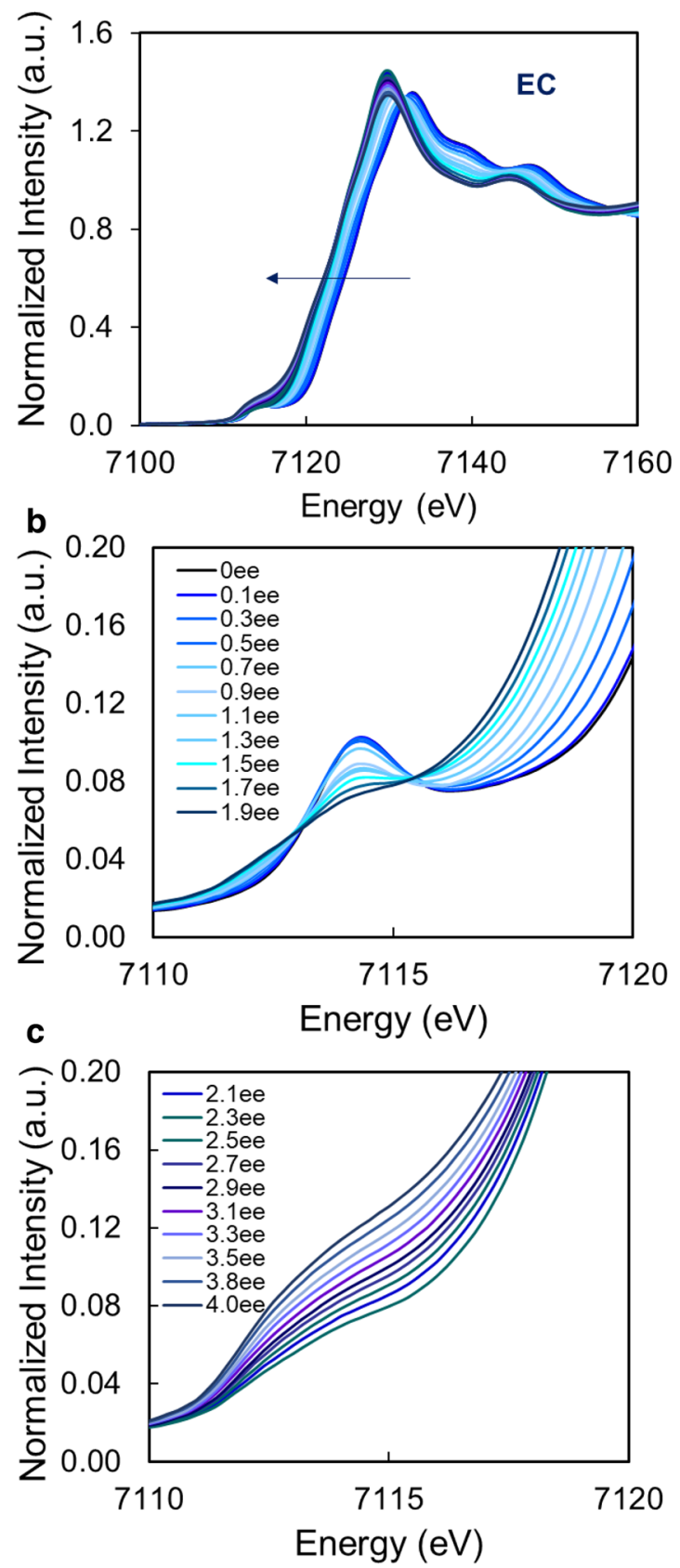

d
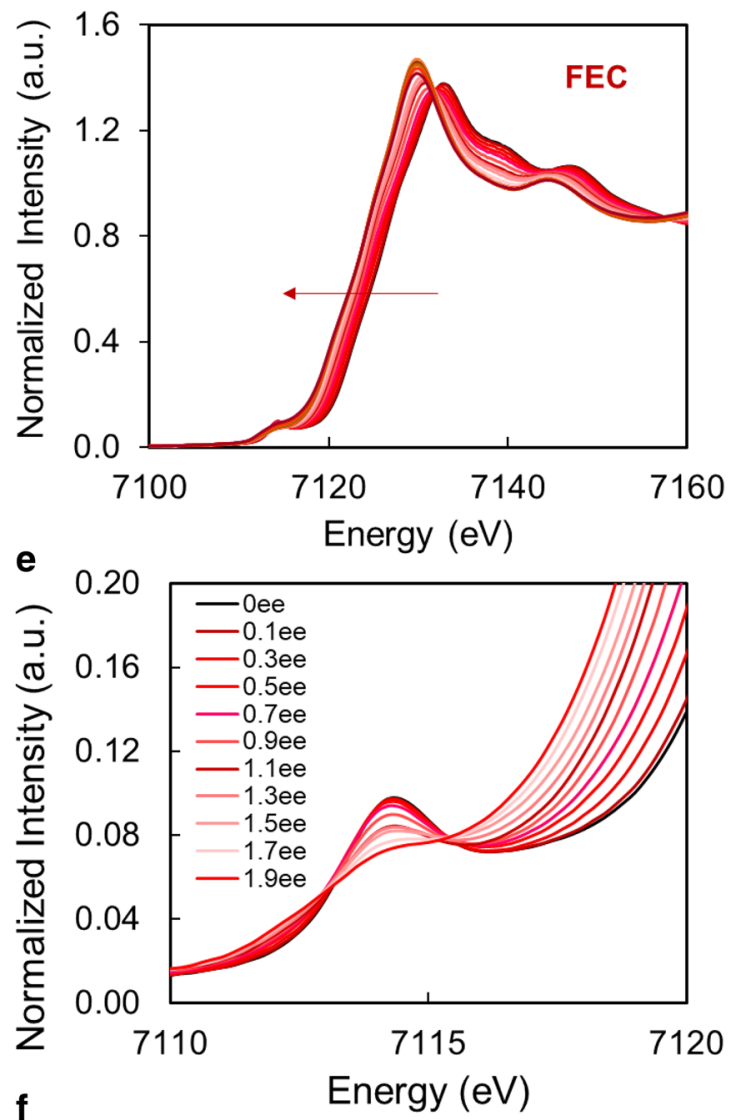

f

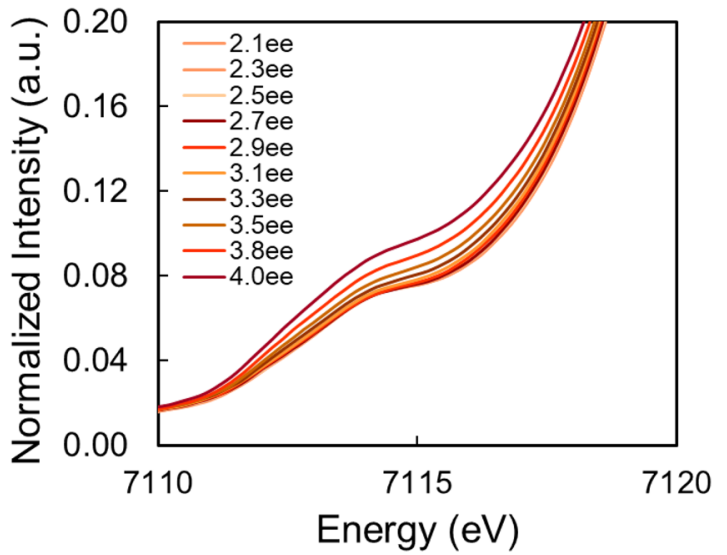

Figure 7: XANES spectra of $\mathrm{Li} / \mathrm{Fe}_{3} \mathrm{O}_{4}$ operando cell with (a)-(c) EC and (d)-(f) FEC electrolyte with highlighted pre-edge feature from (b), (e) 0 to 1.9 ee and (c), (f) 2.1 to 4.0 ee. Arrows indicate increasing electron equivalents.

operando approaches: isothermal microcalorimetry (IMC) and X-ray absorption spectroscopy (XAS). Isothermal microcalorimetry, which measures total heat flow dissipated from a battery during operation, can be analyzed to track onset and evolution of parasitic reactions. These parasitic reactions include interfacial phenomena, such as solid electrolyte interphase (SEI) formation, therefore, making it one of the few techniques that can probe interfaces operando. X-ray absorption spectroscopy
(XAS) is a complimentary bulk operando technique, which can follow reduction and oxidation of a redox active species and changes in local atomic environment of the designated element through the X-ray absorption near edge fine structure (XANES) and extended X-ray absorption fine structure (EXAFS) spectra.

Herein we apply operando IMC and XAS to understand bulk and interfacial changes of $\mathrm{Fe}_{3} \mathrm{O}_{4}$ during lithiation in the presence of EC [1 M LiPF6 EC/DMC (3:7)] and FEC [1 M 

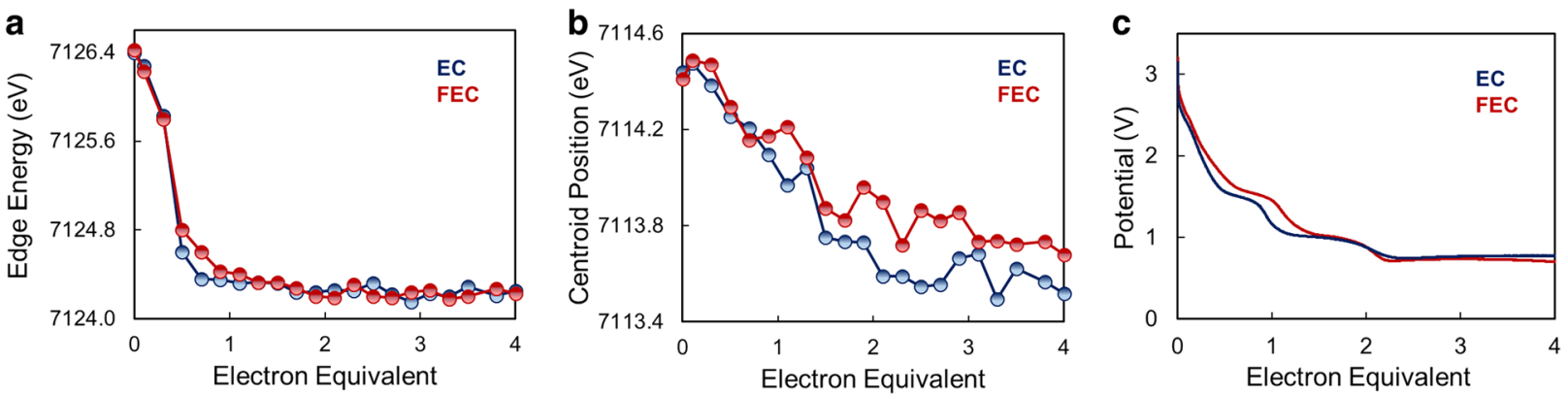

Figure 8: (a) Fe K-edge energy and (b) centroid position of the pre-edge peak as a function of electron equivalents with (c) corresponding electrochemistry of operando $\mathrm{Li} / \mathrm{Fe}_{3} \mathrm{O}_{4}$ cells with EC (blue) and FEC (red) electrolyte.
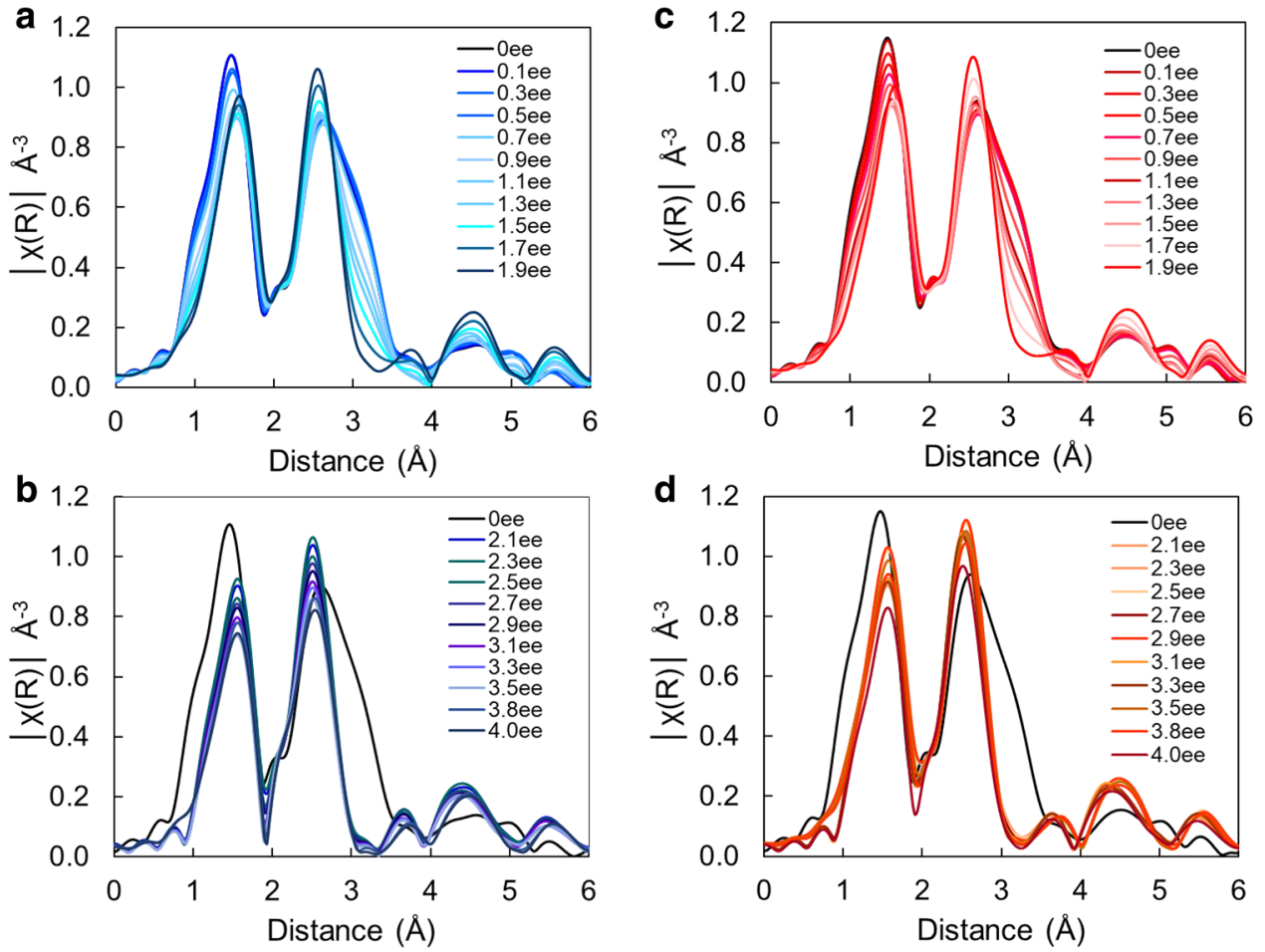

Figure 9: EXAFS spectra of $\mathrm{Li} / \mathrm{Fe}_{3} \mathrm{O}_{4}$ operando cell with (a), (b) EC and (c), (d) FEC electrolyte from (a), (c) 0 to 1.9 ee and (b), (d) 2.1 to 4.0 ee EXAFS plots are not corrected for phase shifts. Interatomic distances shown are $\sim 0.4 \AA$ less than true interatomic distances determined by EXAFS fitting.

LiPF6 FEC/DMC (3:7)] electrolyte. Similarities in the differential capacity (Fig. 4), XANES (Fig. 7) and EXAFS (Fig. 9) profiles of FEC and EC cells suggest the bulk $\mathrm{Fe}_{3} \mathrm{O}_{4}$ lithiation mechanism, Fe oxidation state, and local atomic environment of Fe changes are not impacted by changes in electrolyte. In contrast, dramatic differences in the IMC heat flow profiles before $400 \mathrm{mAh} / \mathrm{g}$ of lithiation (Fig. 4; Table S3) are observed between EC and FEC cells. Analysis of the IMC heat generation and heat flow into polarization, entropic, and parasitic components (Figs. 5, 6; Table S5) indicates the FEC cell generates $7 \%(<2$ ee $)$ and $5 \%(<400 \mathrm{mAh} / \mathrm{g})$ more parasitic heat than the EC cell, consistent with electrolyte reduction at the electrode interface at higher potential. Thus, the IMC and XAS data presented suggests that electrolyte modification influences interfacial phenomena rather than bulk lithiation properties.

This article demonstrates how operando IMC and XAS in tandem can elucidate bulk and interfacial information, leading to a more holistic understanding of the electrode-electrolyte interactions within a conversion electrode. Equipped with knowledge of charge transport phenomena at multiple time and length scales within an EES system, we can expedite solutions for current challenges in energy storage. 


\section{Experimental method}

\section{Synthesis and material characterization}

$\mathrm{Fe}_{3} \mathrm{O}_{4}$ was synthesized via co-precipitation consistent with previous reports, where $\mathrm{FeCl}_{2} \cdot 4 \mathrm{H}_{2} \mathrm{O}_{(\mathrm{aq})}$ and $\mathrm{FeCl}_{3} \cdot 6 \mathrm{H}_{2} \mathrm{O}_{(\mathrm{aq})}$ were added to deoxygenated ammonium hydroxide $\left(\mathrm{NH}_{4} \mathrm{OH}\right)$ and $\mathrm{H}_{2} \mathrm{O}$ [47]. The product was washed with $\mathrm{H}_{2} \mathrm{O}$ until neutral and dried under vacuum at room temperature. X-ray powder diffraction was conducted with a Rigaku Miniflex X-ray diffractometer with a $\mathrm{Cu} \mathrm{Ka}$ source $(\lambda=1.5406 \AA)$. Crystallite size of $\mathrm{Fe}_{3} \mathrm{O}_{4}$ was calculated using the Scherrer equation based on the (220) reflection and corrected for instrumental broadening using a $\mathrm{LaB}_{6}$ standard. The (220) peak was fit with a Pearson VII Area function using the PeakFit software v4.12. Lattice parameters were acquired by refining the powder diffraction pattern using an inverse spinel $\mathrm{Fe}_{3} \mathrm{O}_{4}$ starting structure [38] and the GSAS-II software package [48]. Transmission electron microscopy (TEM) of the as-synthesized $\mathrm{Fe}_{3} \mathrm{O}_{4}$ powder was collected using a JEOL JEM-1400 instrument equipped with a field-emission electron gun that operated at $120 \mathrm{kV}$. Particle size distribution determination used ImageJ image software where 133 particles were chosen for the analysis [49].

\section{Electrochemical measurement}

A slurry of 90 wt.\% $\mathrm{Fe}_{3} \mathrm{O}_{4}$ and 10 wt.\% PVDF in NMP was cast onto copper foil. Stainless-steel coin cells were assembled using the $\mathrm{Fe}_{3} \mathrm{O}_{4}$ cathode, lithium metal anode, polypropylene separators and either $1 \mathrm{M} \mathrm{LiPF}_{6}$ in ethylene carbonate (EC)/dimethyl carbonate $(\mathrm{DMC})(30 / 70 \mathrm{v} / \mathrm{v})$ or $1 \mathrm{M} \mathrm{LiPF}_{6}$ in fluoroethylene carbonate $(\mathrm{FEC}) / \mathrm{DMC}(3 / 7 \mathrm{v} / \mathrm{v})$. The coin cells were used for isothermal microcalorimetry and polarization/entropy tests. All electrochemical measurements used a BioLogic VSP Potentiostat and were conducted at $30^{\circ} \mathrm{C}$.

\section{Isothermal microcalorimetry}

A TA instrument TAM III microcalorimeter was used for IMC measurement and connected to a BioLogic VSP potentiostat via low thermal conductivity wires. The temperature of the IMC oil bath was $30^{\circ} \mathrm{C}$ for all measurements. The cells were lithiated at $40 \mathrm{~mA} / \mathrm{g}$ to $0.3 \mathrm{~V}$.

\section{Polarization heat contribution determination}

Galvanostatic Intermittent Titration Technique (GITT) was employed to estimate the equilibrium potentials of EC- or FEC -containing $\mathrm{Li} / \mathrm{Fe}_{3} \mathrm{O}_{4}$ systems at different lithiation states. $\mathrm{Li} /$ $\mathrm{Fe}_{3} \mathrm{O}_{4}$ cells with EC or FEC electrolytes were discharged to different states of lithiation and then allowed to rest at each state. The experimental GITT curves were further normalized based on lithiation contents of cells cycled in IMC. The open-circuit potential recovery profile was numerically fit to a logarithmic function to extrapolate the open-circuit potential at $500 \mathrm{~h}$. The relaxation potential at $500 \mathrm{~h}$ was used to calculate polarization heat flow at each lithiation increment, as $\mathrm{Fe}_{3} \mathrm{O}_{4}$ electrodes in lithium cells have been shown to reach equilibrium after $500 \mathrm{~h}$ of rest [50]. The polarization heat flow was calculated as the difference between the extrapolated equilibrium potential and loaded voltage multiplied by the discharge current.

\section{Entropic heat flow contribution determination}

Methods for elucidation of entropic heat flow were adapted from those described previously [5]. At each lithiation stage, the opencircuit potential of $\mathrm{Li} / \mathrm{Fe}_{3} \mathrm{O}_{4}$ cells was monitored as temperature changed in a sequence of $30, \sim 25, \sim 35$, and $\sim 30^{\circ} \mathrm{C}$. The OCP-time and temperature-time responses from $25^{\circ} \mathrm{C}$ to $35^{\circ} \mathrm{C}$ was fit to a linear function to determine values of $\mathrm{dE} / \mathrm{dT}$. The entropic heat flow was calculated as the multiplication of the value of $\mathrm{dE} / \mathrm{dT}$, temperature and the current density.

\section{Operando X-ray absorption spectroscopy}

Two in-situ cells were fabricated with a $\mathrm{Fe}_{3} \mathrm{O}_{4} / \mathrm{PVDF}$ (90/10) cathode, polyethylene separator, Li metal anode, and either $1 \mathrm{M}$ $\mathrm{LiPF}_{6}$ in $\mathrm{EC} / \mathrm{DMC}$ or $1 \mathrm{M} \mathrm{LiPF}_{6}$ in FEC/DMC electrolyte. In-situ cells were lithiated at $115 \mathrm{~mA} / \mathrm{g}$ to 4 molar electron equivalents. Operando X-ray absorption spectroscopy (XAS) measurements at the Fe K-edge $(7112 \mathrm{eV})$ were collected in transmission mode and recorded during lithiation of the EC and FEC-containing $\mathrm{Li} / \mathrm{Fe}_{3} \mathrm{O}_{4}$ pouch cells at beamline 7-ID QAS in the National Synchrotron Light Source II within Brookhaven National Laboratory. An iron metal reference foil was collected simultaneously with each measurement and was used for calibration during analysis.

XAS spectra were aligned, normalized, merged, and background subtracted $\left(R_{\mathrm{bkg}}=1.0\right)$ using the Athena software [51, 52]. The edge energy was determined using maximum of the first derivative of $\mu(E)$ spectrum. The pre-edge peak feature from the $\mu(E)$ spectrum was background subtracted using a spline function then fit using two or three Voigt functions analogous to previously reported methods $[45,46]$. Normalized EXAFS spectra were fit using the Artemis program with theoretical structural models (inverse spinel $\mathrm{Fe}_{3} \mathrm{O}_{4}$ [38], rock-salt like $\mathrm{FeO}$, and body-centered cubic Fe metal [53]) created with FEFF6 [52, 54]. The rock-salt like $\mathrm{FeO}$ structure was generated from a non-lithiated $\mathrm{Fe}_{3} \mathrm{O}_{4}$ spinel structure modified so that all Fe centers occupy octahedral $16 \mathrm{c}$ sites. The Fourier transform of $\chi(k)(|\chi(R)|)$ used a $k$-range of $2-11 \AA^{-1}$ and Hanning window ( $\left.\mathrm{d} k=2\right)$. EXAFS fitting was conducted using $k, k^{2}$, and $k^{3}$ weights simultaneously and an $R$-range of 1-3.5 Å to fully encompass the first and second shells of $|\chi(R)|$. 


\section{Acknowledgments}

Materials synthesis, characterization, electrochemistry, and isothermal microcalorimetry were supported by the Center for Mesoscale Transport Properties, an Energy Frontier Research Center supported by the DOE-BES, under Award \#DE-SC0012673. The XAS measurements used the Quick $\mathrm{X}$-ray Absorption and Scattering (QAS) 7-BM beamline at the National Synchrotron Light Source II, a U.S. Department of Energy (DOE) Office of Science User Facility operated for the DOE Office of Science by Brookhaven National Laboratory under Contract DE-SC0012704. G.D.R acknowledges the support of the Turner Fellowship Program. E.S.T. acknowledges funding from the William and Jane Knapp Chair for Energy and the Environment.

\section{Data availlability}

Relevant data for analysis, including the detailed results and approaches for IMC and XAS analysis, are provided as part of supplementary information.

\section{Declarations}

Conflict of interest The authors declare no conflict of interest.

\section{Open Access}

This article is licensed under a Creative Commons Attribution 4.0 International License, which permits use, sharing, adaptation, distribution and reproduction in any medium or format, as long as you give appropriate credit to the original author(s) and the source, provide a link to the Creative Commons licence, and indicate if changes were made. The images or other third party material in this article are included in the article's Creative Commons licence, unless indicated otherwise in a credit line to the material. If material is not included in the article's Creative Commons licence and your intended use is not permitted by statutory regulation or exceeds the permitted use, you will need to obtain permission directly from the copyright holder. To view a copy of this licence, visit http://creativecommons.org/ licenses/by/4.0/.

\section{Supplementary Information}

The online version contains supplementary material available at https://doi.org/10.1557/s43578-021-00350-y.

\section{References}

1. W. Li, D.M. Lutz, L. Wang, K.J. Takeuchi, A.C. Marschilok, E.S. Takeuchi, Peering into batteries: electrochemical insight through in situ and operando methods over multiple length scales. Joule 5(1), 77 (2020)

2. G. Assat, S.L. Glazier, C. Delacourt, J.-M. Tarascon, Probing the thermal effects of voltage hysteresis in anionic redox-based lithium-rich cathodes using isothermal calorimetry. Nat. Energy 4(8), 647 (2019)

3. L.E. Downie, S.R. Hyatt, A.T.B. Wright, J.R. Dahn, Determination of the time dependent parasitic heat flow in lithium ion cells using isothermal microcalorimetry. J. Phys. Chem. C 118(51), 29533 (2014)

4. J. Li, L.E. Downie, L. Ma, W. Qiu, J.R. Dahn, Study of the failure mechanisms of $\mathrm{LiNi}_{0.8} \mathrm{Mn}_{0.1} \mathrm{Co}_{0.1} \mathrm{O}_{2}$ cathode material for lithium ion batteries. J. Electrochem. Soc. 162(7), A1401 (2015)

5. L.M. Housel, W. Li, C.D. Quilty, M.N. Vila, L. Wang, C.R. Tang, D.C. Bock, Q. Wu, X. Tong, A.R. Head, K.J. Takeuchi, A.C. Marschilok, E.S. Takeuchi, Insights into reactivity of silicon negative electrodes: analysis using isothermal microcalorimetry. ACS Appl. Mater. Interfaces. 11(41), 37567 (2019)

6. J.Q. Huang, L.A. Blanquer, J. Bonefacino, E.R. Logan, D.A.D. Corte, C. Delacourt, B.M. Gallant, S.T. Boles, J.R. Dahn, H.Y. Tam, J.M. Tarascon, Operando decoding of chemical and thermal events in commercial $\mathrm{Na}(\mathrm{Li})$-ion cells via optical sensors. Nat. Energy. 5(9), 674 (2020)

7. D. Bernardi, E. Pawlikowski, J. Newman, A general energy balance for battery systems. J. Electrochem. Soc. 132(1), 5 (1985)

8. L. Rao, J. Newman, Heat-generation rate and general energy balance for insertion battery systems. J. Electrochem. Soc. 144(8), 2697 (1997)

9. K.E. Thomas, J. Newman, Thermal modeling of porous insertion electrodes. J. Electrochem. Soc. 150(2), A176 (2003)

10. A.V. Virkar, J. Chen, C.W. Tanner, J.W.J. Kim, The role of electrode microstructure on activation and concentration polarizations in solid oxide fuel cells. Solid State Ionics 131(1-2), 189 (2000)

11. Y. Reynier, J. Graetz, T. Swan-Wood, P. Rez, R. Yazami, B. Fultz, Entropy of liintercalation in $\mathrm{LixCoO}_{2}$. Phys. Rev. B. 70(17), 174304 (2004)

12. M.P. Mercer, S. Finnigan, D. Kramer, D. Richards, H.E. Hoster, The influence of point defects on the entropy profiles of lithium ion battery cathodes: a lattice-gas Monte Carlo study. Electrochim. Acta 241, 141 (2017)

13. K. Xu, Electrolytes and interphases in Li-Ion batteries and beyond. Chem. Rev. 114(23), 11503 (2014)

14. L.M. Housel, A. Abraham, G.D. Renderos, K.J. Takeuchi, E.S. Takeuchi, A.C. Marschilok, Surface electrolyte interphase control on magnetite, $\mathrm{Fe}_{3} \mathrm{O}_{4}$, electrodes: impact on electrochemistry. MRS Adv. 3(11), 581 (2018)

15. M. Sina, R. Thorpe, S. Rangan, N. Pereira, R.A. Bartynski, G.G. Amatucci, F. Cosandey, Investigation of SEI layer formation in 
conversion iron fluoride cathodes by combined STEM/EELS and XPS. J. Phys. Chem. C. 119(18), 9762 (2015)

16. D.C. Bock, G.H. Waller, A.N. Mansour, A.C. Marschilok, K.J. Takeuchi, E.S. Takeuchi, Investigation of solid electrolyte interphase layer formation and electrochemical reversibility of magnetite, $\mathrm{Fe}_{3} \mathrm{O}_{4}$, electrodes: a combined X-ray absorption spectroscopy and X-ray photoelectron spectroscopy study. J.

Phys. Chem. C 122(26), 14257 (2018)

17. S.H. Lee, S.-H. Yu, J.E. Lee, A. Jin, D.J. Lee, N. Lee, H. Jo, K. Shin, T.-Y. Ahn, Y.-W. Kim, H. Choe, Y.-E. Sung, T. Hyeon, Self-assembled $\mathrm{Fe}_{3} \mathrm{O}_{4}$ nanoparticle clusters as high-performance anodes for lithium ion batteries via geometric confinement. Nano Lett. 13(9), 4249 (2013)

18. W.-M. Zhang, X.-L. Wu, J.-S. Hu, Y.-G. Guo, L.-J. Wan, Carbon coated $\mathrm{Fe}_{3} \mathrm{O}_{4}$ nanospindles as a superior anode material for lithium-ion batteries. Adv. Funct. Mater. 18(24), 3941 (2008)

19. C.P. Grey, J.M. Tarascon, Sustainability and in situ monitoring in battery development. Nat Mater. 16(1), 45 (2016)

20. D.C. Bock, A.C. Marschilok, K.J. Takeuchi, E.S. Takeuchi, Deliberate modification of the solid electrolyte interphase (SEI) during lithiation of magnetite, $\mathrm{Fe}_{3} \mathrm{O}_{4}$ : impact on electrochemistry. Chem. Commun (Camb., UK). 53(98), 13145 (2017)

21. L. Hu, Z. Zhang, K. Amine, Fluorinated electrolytes for Li-ion battery: an FEC-based electrolyte for high voltage $\mathrm{LiNi}_{0.5} \mathrm{Mn}_{1.5} \mathrm{O} 4 /$ graphite couple. Electrochem. Commun. 35, 76 (2013)

22. T. Hou, G. Yang, N.N. Rajput, J. Self, S.-W. Park, J. Nanda, K.A. Persson, The influence of FEC on the solvation structure and reduction reaction of LiPF6/EC electrolytes and its implication for solid electrolyte interphase formation. Nano Energy 64, 103881 (2019)

23. D. Aurbach, A. Schechter, Changes in the resistance of electrolyte solutions during contact with lithium electrodes at open circuit potential that reflect the Li surface chemistry. Electrochim. Acta 46(15), 2395 (2001)

24. S. Zhang, M. He, C.-C. Su, Z. Zhang, Advanced electrolyte/additive for lithium-ion batteries with silicon anode. Curr. Opin. Chem. Eng. 13, 24 (2016)

25. K. Tasaki, K. Kanda, T. Kobayashi, S. Nakamura, M. Ue, Theoretical studies on the reductive decompositions of solvents and additives for lithium-ion batteries near lithium anodes. J. Electrochem. Soc. 153(12), A2192 (2006)

26. I.A. Shkrob, J.F. Wishart, D.P. Abraham, What makes fluoroethylene carbonate different? J. Phys. Chem. C 119(27), 14954 (2015)

27. K. Schroder, J. Alvarado, T.A. Yersak, J. Li, N. Dudney, L.J. Webb, Y.S. Meng, K.J. Stevenson, The effect of fluoroethylene carbonate as an additive on the solid electrolyte interphase on silicon lithium-ion electrodes. Chem. Mater. 27(16), 5531 (2015)
28. C.C. Nguyen, B.L. Lucht, Comparative study of fluoroethylene carbonate and vinylene carbonate for silicon anodes in lithium ion batteries. J. Electrochem. Soc. 161(12), A1933 (2014)

29. L.J. Krause, V.L. Chevrier, L.D. Jensen, T. Brandt, The effect of carbon dioxide on the cycle life and electrolyte stability of Li-Ion full cells containing silicon alloy. J. Electrochem. Soc. 164(12), A2527 (2017)

30. N.-S. Choi, K.H. Yew, K.Y. Lee, M. Sung, H. Kim, S.-S. Kim, Effect of fluoroethylene carbonate additive on interfacial properties of silicon thin-film electrode. J. Power Sources 161(2), 1254 (2006)

31. C. Xu, F. Lindgren, B. Philippe, M. Gorgoi, F. Björefors, K. Edström, T. Gustafsson, Improved performance of the silicon anode for Li-Ion batteries: understanding the surface modification mechanism of fluoroethylene carbonate as an effective electrolyte additive. Chem. Mater. 27(7), 2591 (2015)

32. C. Wang, H. Wu, Z. Chen, M.T. McDowell, Y. Cui, Z. Bao, Self-healing chemistry enables the stable operation of silicon microparticle anodes for high-energy lithium-ion batteries Nat. Chem. 5(12), 1042 (2013)

33. V. Etacheri, O. Haik, Y. Goffer, G.A. Roberts, I.C. Stefan, R. Fasching, D. Aurbach, Effect of fluoroethylene carbonate (FEC) on the performance and surface chemistry of Si-nanowire Li-Ion battery anodes. Langmuir 28(1), 965 (2012)

34. R. Jung, M. Metzger, D. Haering, S. Solchenbach, C. Marino, N. Tsiouvaras, C. Stinner, H.A. Gasteiger, Consumption of fluoroethylene carbonate (FEC) on Si-C composite electrodes for Li-Ion batteries. J. Electrochem. Soc. 163(8), A1705 (2016)

35. H. Nakai, T. Kubota, A. Kita, A. Kawashima, Investigation of the solid electrolyte interphase formed by fluoroethylene carbonate on Si electrodes. J. Electrochem. Soc. 158(7), A798 (2011)

36. S.A. Webb, L. Baggetto, C.A. Bridges, G.M. Veith, The electrochemical reactions of pure indium with $\mathrm{Li}$ and $\mathrm{Na}$ : anomalous electrolyte decomposition, benefits of FEC additive, phase transitions and electrode performance. J. Power Sources 248, 1105 (2014)

37. L. Ji, M. Gu, Y. Shao, X. Li, M.H. Engelhard, B.W. Arey, W. Wang, Z. Nie, J. Xiao, C. Wang, Controlling SEI formation on $\mathrm{SnSb}$-porous carbon nanofibers for improved $\mathrm{Na}$ ion storage. Adv. Mater. 26(18), 2901 (2014)

38. M.E. Fleet, The structure of magnetite: two annealed natural magnetites, $\mathrm{Fe}_{3.005} \mathrm{O} 4$ and $\mathrm{Fe}_{2.96} \mathrm{Mg}_{0.4} \mathrm{O}_{4}$. Acta Crystallogr. 40, 1491 (1984)

39. A.M. Bruck, C.A. Cama, C.N. Gannett, A.C. Marschilok, E.S. Takeuchi, K.J. Takeuchi, Nanocrystalline iron oxide based electroactive materials in lithium ion batteries: the critical role of crystallite size, morphology, and electrode heterostructure on battery relevant electrochemistry. Inorg. Chem. Front. 3(1), 26 (2016) 
40. C. Zhao, Y. Ma, C. Shen, W. Han, Electrodeposition of $\mathrm{Fe}_{3} \mathrm{O}_{4}$ thin film and its application as anode for lithium ion batteries. J. Nanosci. Nanotechnol. 16(1), 950 (2016)

41. S. Wang, W. Zhang, Y. Chen, Z. Dai, C. Zhao, D. Wang, C. Shen, Operando study of $\mathrm{Fe}_{3} \mathrm{O}_{4}$ anodes by electrochemical atomic force microscopy. Appl. Surf. Sci. 426, 217 (2017)

42. S.L. Zhu, A.C. Marschilok, E.S. Takeuchi, K.J. Takeuchi, Crystallite size control and resulting electrochemistry of magnetite, $\mathrm{Fe}_{3} \mathrm{O}_{4}$. Electrochem. Solid State Lett. 12(4), a91 (2009)

43. S.L. Zhu, A.C. Marschilok, E.S. Takeuchi, G.T. Yee, G.B. Wang, K.J. Takeuchi, Nanocrystalline magnetite: synthetic crystallite size control and resulting magnetic and electrochemical properties. J. Electrochem. Soc. 157(11), A1158 (2010)

44. M.W. Chase Jr., NIST-JANAF thermochemical tables. J. Phys. Chem. Ref. Data. Monograph 9, 1 (1998)

45. S.H. Choi, B.R. Wood, J.A. Ryder, A.T. Bell, X-ray absorption fine structure characterization of the local structure of Fe in Fe-ZSM-5. J. Phys. Chem. B 107(43), 11843 (2003)

46. P.E. Petit, F. Farges, M. Wilke, V.A. Solé, Determination of the iron oxidation state in earth materials using XANES pre-edge information. J. Synchrotron Radiat. 8(Pt 2), 952 (2001)

47. S. Zhu, A.C. Marschilok, E.S. Takeuchi, K.J. Takeuchi, Crystallite size control and resulting electrochemistry of magnetite, $\mathrm{Fe}_{3} \mathrm{O}_{4}$. Electrochem. Solid-State Lett. 12(4), A91 (2009)
48. B. Toby, R. Dreele, GSAS-II: the genesis of a modern opensource all-purpose crystallography software package. J. Appl. Crystallogr. 46, 544 (2013)

49. C.A. Schneider, W.S. Rasband, K.W. Eliceiri, NIH Image to ImageJ: 25 years of image analysis. Nat. Methods 9(7), 671 (2012)

50. K.W. Knehr, N.W. Brady, C.A. Cama, D.C. Bock, Z. Lin, C.N. Lininger, A.C. Marschilok, K.J. Takeuchi, E.S. Takeuchi, A.C. West, Modeling the mesoscale transport of lithium-magnetite electrodes using insight from discharge and voltage recovery experiments. J. Electrochem. Soc. 162(14), A2817 (2015)

51. M.J. Newville, IFEFFIT: interactive XAFS analysis and FEFF fitting. J. Synchrotron Radiat. 8, 322 (2001)

52. B. Ravel, M.J. Newville, Athena, Artemis, Hephaestus: data analysis for X-ray absorption spectroscopy using IFEFFIT. J. Synchrotron Radiat. 12, 537 (2005)

53. E.A. Owens, E.L. Yates, Precision measurements of crystal parameters. Phil. Mag. 15, 472 (1933)

54. J.J. Rehr, J. Mustre de Leon, S.I. Zabinsky, R.C. Albers, Theoretical X-ray absorption fine structure standards. J. Am. Chem. Soc. 113, 5135 (1991) 